\title{
Energetic Constraints on Precipitation Under Climate Change
}

\author{
Paul A. O'Gorman • Richard P. Allan • Michael P. Byrne • \\ Michael Previdi
}

Received: 17 August 2011/Accepted: 2 November 2011/Published online: 23 November 2011

(C) Springer Science+Business Media B.V. 2011

\begin{abstract}
Energetic constraints on precipitation are useful for understanding the response of the hydrological cycle to ongoing climate change, its response to possible geoengineering schemes, and the limits on precipitation in very warm climates of the past. Much recent progress has been made in quantifying the different forcings and feedbacks on precipitation and in understanding how the transient responses of precipitation and temperature might differ qualitatively. Here, we introduce the basic ideas and review recent progress. We also examine the extent to which energetic constraints on precipitation may be viewed as radiative constraints and the extent to which they are confirmed by available observations. Challenges remain, including the need to better demonstrate the link between energetics and precipitation in observations and to better understand energetic constraints on precipitation at sub-global length scales.
\end{abstract}

Keywords Precipitation - Global change $\cdot$ Energetics

\section{Introduction}

It is not surprising that energetics play an important role in determining global-mean precipitation given that surface evaporation is ultimately driven by solar radiation. ${ }^{1}$

\footnotetext{
1 See Peixoto and Oort (1992), Trenberth et al. (2009), and Stevens and Schwartz (2011) for reviews of the energy budget of the Earth.
}

P. A. O’Gorman $(\bowtie) \cdot$ M. P. Byrne

Department of Earth, Atmospheric, and Planetary Sciences, Massachusetts Institute of Technology,

77 Massachusetts Avenue, Cambridge, MA 02139, USA

e-mail: pog@mit.edu

R. P. Allan

Department of Meteorology, National Centre for Atmospheric Science, University of Reading, Reading, UK

M. Previdi

Lamont-Doherty Earth Observatory, Columbia University, 61 Route 9W, Palisades, NY 10964, USA 
Fig. 1 Schematic of the energy budgets of the atmosphere and of the atmosphere above cloud base, as described in the text; LCL is the lifted condensation level. [Following Fig. 1 of Takahashi (2009a)]

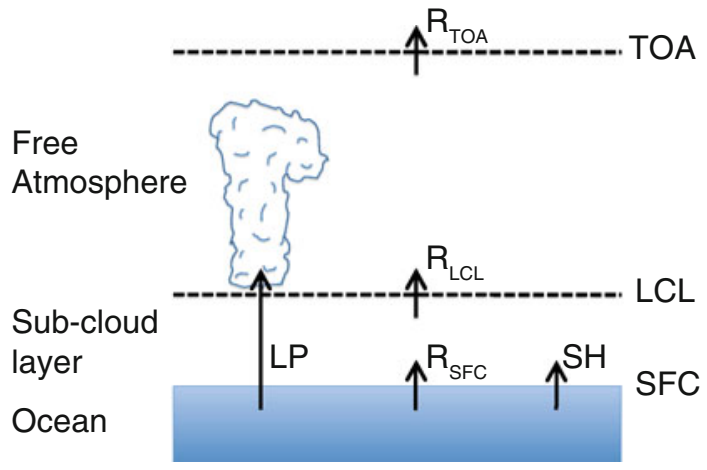

In the context of climate change, we speak of energetics placing a constraint on precipitation in the sense that precipitation must change in such a way that the energy budget of the atmosphere (or the surface) continues to balance. We will work primarily with the energy budget of the atmosphere because its relatively small heat capacity facilitates analysis of transient changes in precipitation; the surface energy budget may also be usefully analyzed in a climate change context (Boer 1993; Richter and Xie 2008; Andrews et al. 2009; Lorenz et al. 2010). A schematic view of the global atmospheric energy budget is shown in Fig. 1. We begin by considering the energy budget of the entire atmosphere from the surface to the top of the atmosphere. The perturbation budget between two climates may be written as

$$
L \delta P=\delta R_{\mathrm{TOA}}-\delta R_{\mathrm{SFC}}-\delta S H
$$

where $L$ is the latent heat of condensation (assumed constant for simplicity), $P$ is the precipitation rate, $R_{\mathrm{TOA}}$ and $R_{\mathrm{SFC}}$ are the net radiation fluxes at the top of the atmosphere (TOA) and at the surface (SFC), respectively, $S H$ is the surface sensible heat flux, and $\delta$ denotes the difference between the two climates. ${ }^{2}$ Thus, changes in precipitation are directly related to changes in the radiative cooling of the atmosphere and the surface sensible heat flux. For a change in surface temperature, the resulting change in radiative cooling may be calculated to first order by assuming invariant relative humidity and a moist adiabatic lapse rate in the free troposphere. More generally, the changes in all radiative forcing agents, surface air temperature difference, and surface sensible heat flux must also be taken into account. This energetic approach is often more straightforward than understanding the precipitation response in terms of changes in large-scale circulations or convective mass fluxes that are themselves mediated by relatively subtle changes in atmospheric stability.

The energetic constraint described above was already discussed in some detail in the early work of Mitchell et al. (1987). Allen and Ingram (2002) showed how it could be used to understand the response of precipitation to climate change in different climate model simulations, and Pierrehumbert (2002) showed how the surface energy budget constrained precipitation in very warm climates. More recently, there has been considerable progress in using the energetic perspective to better quantify and understand several aspects of the response of precipitation to climate change: the feedbacks influencing the rate of change of precipitation under warming (e.g., Stephens and Ellis 2008; Previdi 2010), how the

\footnotetext{
${ }^{2}$ Positive fluxes of energy are upwards and all fluxes are averaged globally and over sufficiently long times that we may neglect changes in energy and water storage in the energy budget of a given climate state.
} 
response of precipitation varies depending on the climate forcing agent (e.g., Andrews et al. 2010), and how precipitation responds on "fast" and "slow" timescales (e.g., Lambert and Faull 2007; Bala et al. 2010). In all of these cases, it is useful and natural to think of precipitation and evaporation as energy fluxes. Even for regional changes in precipitation, it is possible to usefully adopt an energetic approach (Muller and O'Gorman 2011).

The energetic constraint does not suggest that global-mean precipitation scales with the amount of water vapor in the atmosphere, although water vapor does play an important radiative role and can, therefore, be related to changes in precipitation through energetic arguments (Stephens and Ellis 2008; Allan 2009; Stephens and Hu 2010). Precipitation intensity or precipitation extremes, on the other hand, could be expected to be more directly affected by changes in water vapor concentrations and increase with warming at a faster rate than global-mean precipitation (Allen and Ingram 2002; Trenberth et al. 2003; Pall et al. 2007); recent results suggest that vertical gradients of specific humidity or surface specific humidities are relevant for precipitation extremes (O'Gorman and Schneider 2009a, b; Schneider et al. 2010; Muller et al. 2011; Romps 2011). Several authors have argued that this implies a reduction in the overall frequency of precipitation (e.g., Trenberth 1999, 2011; Allen and Ingram 2002; Trenberth et al. 2003; Stephens and $\mathrm{Hu}$ 2010). Decreases in precipitation frequency are seen in the subtropics in model simulations of warmed climates (e.g., Sun et al. 2007), and there is observational evidence for decreases in mean precipitation in tropical regions with mean descent (e.g., Allan et al. 2010), but it is important to note that the precipitation distribution could adjust in ways other than a simple decrease in frequency (Muller et al. 2011). Similar arguments have been made for a decrease in the strength of the circulation (e.g., Held and Soden 2006), although, again, the required magnitude of the circulation change is difficult to estimate from first principles (Schneider et al. 2010). We do not pursue the implications for precipitation frequency or circulation changes further, but rather focus on the radiative or energetic constraints themselves.

The purpose of this paper is to provide an overview of the modern understanding of energetic constraints on precipitation under climate change, to describe some of the major recent developments, and to examine in detail some of the key open questions. We begin by discussing the extent to which the atmospheric energetic constraint on global-mean precipitation may be viewed as a radiative constraint (Sect. 2) and to what extent energetics place an upper bound on global-mean precipitation (Sect. 3). We discuss the factors contributing to the rate of change of precipitation under climate change (Sect. 4), how these combine to determine the transient precipitation response (Sect. 5), and how the energetic perspective on precipitation changes may be extended to regional precipitation (Sect. 6). We then address the important issue of the extent to which observed changes in precipitation may be related to observed changes in net radiative cooling (Sect. 7). We conclude with a summary and a discussion of remaining challenges (Sect. 8).

\section{Radiative or Energetic Constraint?}

The energetic constraint on global-mean precipitation is often thought of as a radiative constraint in which latent heat release balances radiative cooling, but it clearly also involves the surface sensible heat flux (Eq. 1). Changes in surface sensible heat flux under climate change are not negligible; the upward sensible heat flux decreases in climate model simulations of greenhouse-gas driven warming (O'Gorman and Schneider 2008; Stephens 
and Ellis 2008; Liepert and Previdi 2009; Bala et al. 2010) and in response to increases in insolation (Bala et al. 2010), but may increase with warming in response to aerosol forcing (Liepert and Previdi 2009). One might, therefore, question if the radiative cooling of the atmosphere is really a constraint on precipitation, since the sensible heat flux could in principle adjust to accommodate a given radiative cooling (e.g., by changes in the air-sea temperature difference), so that a minimal model of the atmospheric or surface energy balance must take into account boundary layer transfer in order to constrain precipitation (Pierrehumbert 2002; Le Hir et al. 2009). Takahashi (2009a) proposed a simple model that avoids some of these difficulties by working with the atmospheric energy balance above cloud base (Fig. 1). Assuming that condensation only occurs above the lifted condensation level (LCL), it may be argued that the primary relevant balance is between latent heating and the radiative cooling above the LCL

$$
L \delta P \simeq \delta R_{\mathrm{TOA}}-\delta R_{\mathrm{LCL}} .
$$

This approximate balance relies on the lower level used (nominally the LCL) being below the level of substantial latent heating and above the level of substantial boundary layer dry sensible heat fluxes. It also neglects vertical dry static energy fluxes across the LCL associated with the large-scale circulation. We will refer to it as the free-atmospheric radiative constraint on precipitation (even though the LCL and the top of the boundary layer need not coincide).

Here, we test the accuracy of the free-atmospheric radiative constraint on precipitation in statistical-equilibrium simulations with an idealized general circulation model (GCM) over a wide range of climates (Fig. 2). The GCM is based on a version of the Geophysical Fluid Dynamics Laboratory (GFDL) dynamical core, but with simplified moist parameterizations,
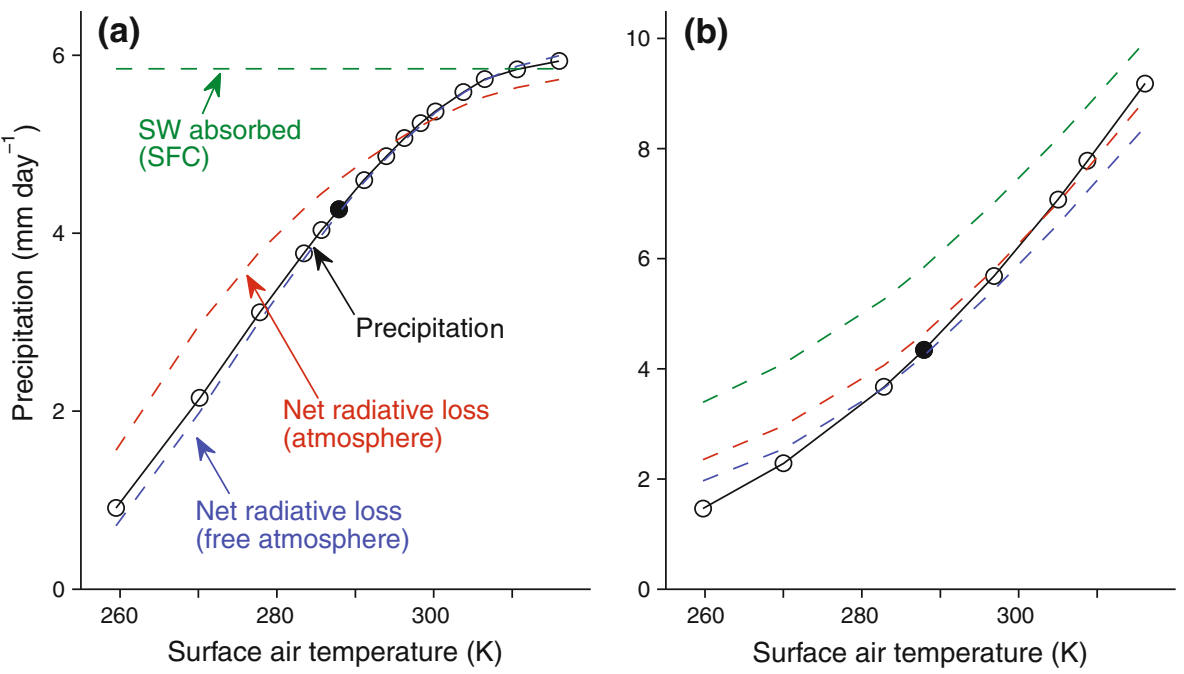

Fig. 2 Global-mean precipitation (solid line with circles) versus global-mean surface air temperature in two series of statistical-equilibrium simulations with an idealized GCM in which a the optical depth of the longwave absorber is varied and $\mathbf{b}$ the solar constant is varied. The filled circles indicate the reference simulation (common to both series) which has the climate most similar to present-day Earth's. The red dashed lines show the net radiative loss of the atmosphere, the blue dashed lines show the net radiative loss of the free atmosphere (above $\sigma=0.86$ ), and the green dashed lines show the net absorbed solar radiation at the surface (all in equivalent precipitation units of $\mathrm{mm}^{\text {day }}{ }^{-1}$ ) 
a two-stream semi-gray radiation scheme without cloud radiative effects, and a slab-ocean lower boundary condition (Frierson et al. 2006; Frierson 2007; O'Gorman and Schneider 2008). The climate is varied in one set of simulations by changing the longwave optical depth to mimic changes in greenhouse-gas concentrations with shortwave (SW) radiative heating held constant (Fig. 2a), as described in O'Gorman and Schneider (2008). We also present a new set of simulations in which the climate is varied by changing the solar constant over a range from 0.58 to 1.70 of the reference value (Fig. 2b). Although the radiation scheme is highly simplified, these simulations serve to illustrate the basic role of energetic constraints on precipitation over a wide range of climates-more realistic radiative transfer will be discussed in later sections. In addition, the GCM includes processes (boundary-layer turbulence and large-scale circulations) that could cause the free-atmospheric radiative constraint on global-mean precipitation (Eq. 2) to be inaccurate, and as such the idealized simulations provide a test of this constraint.

Global-mean precipitation increases with warming for both sets of simulations (Fig. 2a, b). The behavior in the limits of very low and high temperatures is broadly consistent with what might be expected from a simple analysis of the surface energy balance using bulk transfer formulae (Pierrehumbert 2002): precipitation tends to zero for sufficiently low temperatures because of low-specific humidities, and precipitation is limited at high temperatures by the availability of solar radiation at the surface (as discussed in the next section). In the "greenhouse-gas" simulations, the approximation of global-mean precipitation by the net radiative loss of the atmosphere (the dashed red line in Fig. 2a) is not accurate because of substantial changes in the surface sensible heat flux over the range of climates. The net radiative loss of the free atmosphere gives much better agreement (the dashed blue line in Fig. 2a). The free atmosphere is defined here as the atmosphere above the level $\sigma=0.86$, where $\sigma$ is pressure normalized by surface pressure. This level is chosen to give the best overall fit of radiative loss to precipitation and is taken to be representative of the nominal LCL in the approximate radiative constraint given by Eq. 2 . But, the global-mean LCL is actually lower in the atmosphere $(\sigma \simeq 0.93)$, a discrepancy which likely relates to the occurrence of substantial boundary layer fluxes at levels somewhat higher than the LCL. The rate of change of global-mean precipitation is $2.5 \% \mathrm{~K}^{-1}$ near the reference climate (the climate most similar to present-day Earth), compared to $1.5 \% \mathrm{~K}^{-1}$ for the net radiative loss of the atmosphere and $2.6 \% \mathrm{~K}^{-1}$ for the net radiative loss of the free atmosphere. The improvement gained from considering the free atmosphere is not as great in the solar series of simulations, but the overall accuracy of the free-atmospheric radiative constraint is not much worse; the rates of change at the reference climate are $3.2 \% \mathrm{~K}^{-1}$ for precipitation, $2.6 \% \mathrm{~K}^{-1}$ for the net radiative loss of the atmosphere, and $2.9 \% \mathrm{~K}^{-1}$ for the net radiative loss of the free atmosphere.

Our results provide some support for the approximation of global-mean precipitation under climate change using the net radiative loss of the free atmosphere. We will also find this to be a useful approximation in Sect. 4.2 when considering the effect on precipitation of black carbon aerosols at different levels in the atmosphere.

\section{Upper Bound on Precipitation}

Figure $2 \mathrm{a}$ shows that the rate of growth of global-mean precipitation with temperature declines sharply in the very warm climates of the "greenhouse-gas" series of simulations, despite the quasi-exponential increase with temperature of atmospheric water vapor content (O'Gorman and Schneider 2008), and suggesting the possibility of an upper bound on 
precipitation for a given solar constant (Pierrehumbert 1999, 2002; O'Gorman and Schneider 2008). In very warm climates, the atmosphere is optically thick in the longwave and the net longwave radiative flux at the surface becomes small. As discussed by Pierrehumbert (2002), the boundary layer becomes stable (with the near-surface air temperature greater than the surface temperature), and boundary layer turbulence is suppressed. To the extent that the surface sensible heat flux is small, the surface energy budget implies that the surface latent heat flux should then be equal to the absorbed shortwave radiation at the surface, corresponding to the horizontal line in Fig. 2a (the shortwave fluxes are held constant in this idealized set of simulations). The absorbed shortwave radiation is not exactly an upper bound because the surface sensible heat flux becomes directed downward providing additional energy for the evaporation of water (Pierrehumbert 2002). Similarly, in the simulations in which the solar constant is increased, precipitation approaches (but does not reach) the limit given by the absorbed shortwave radiation at the surface (Fig. 2b).

Thus, the energetic constraint on precipitation becomes relatively simple in the limit of very warm climates, although the exact amount of precipitation achievable may depend on poorly understood details of boundary-layer turbulence and radiative transfer. It is useful to remember the limiting case of very warm climates when considering the differences in scaling of water vapor concentrations and precipitation and, as discussed in the next section, the different responses of precipitation to solar and $\mathrm{CO}_{2}$ forcings. The upper bound on global-mean precipitation given by the absorbed surface shortwave radiation is also relevant to very warm climates of the past, in which continental runoff plays an important role in the weathering thermostat (Pierrehumbert 2002; Le Hir et al. 2009). Le Hir et al. (2009) found that global-mean precipitation and continental runoff behaved similarly in the global mean as the climate changed, but it is not clear that this is a general result, and a better understanding of the constraints on precipitation over land is desirable.

\section{Contributions to Changes in Precipitation}

We next discuss the different contributions to changes in precipitation and how they lead to different responses of precipitation compared with temperature depending on the forcing agent. The response of global-mean precipitation to temperature change is clearly quite different for greenhouse-gas versus solar forcing, as evidenced by the leveling-off of precipitation at high temperatures in Fig. 2a compared with the continuous growth in Fig. 2b. Figure 3 [reproduced from Andrews et al. (2009)] shows a similar difference in behavior, but now for subsequent years following an instantaneous doubling of $\mathrm{CO}_{2}$ or an instantaneous increase in solar irradiance in an atmospheric GCM coupled to a slab ocean. The response to $\mathrm{CO}_{2}$ forcing is characterized by an initial decrease in precipitation, followed by a quasi-linear increase with temperature (e.g., Yang et al. 2003; Andrews et al. 2009). The response to solar forcing has a similar form but with a smaller initial decrease (extrapolating the precipitation curve to zero temperature change). As a result, the hydrological sensitivity, defined as the ratio of precipitation change to temperature change, is quite different at equilibrium for the $\mathrm{CO}_{2}$ and solar forcings (compare the dotted lines in Fig. 3). ${ }^{3}$ But, note that the slopes of the precipitation curves are similar for both forcings

\footnotetext{
3 Interestingly, if the hydrological sensitivity is instead defined in terms of TOA radiative forcing rather than temperature change, it is not very different between solar and $\mathrm{CO}_{2}$ forcing (Lambert and Faull 2007).
} 


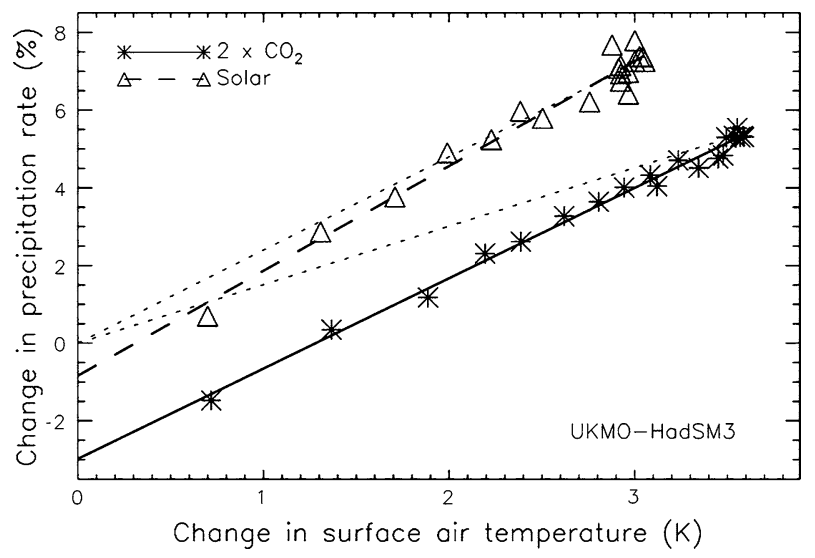

Fig. 3 Change in global-mean precipitation versus change in global-mean surface air temperature averaged over individual years subsequent to an instantaneous increase in $\mathrm{CO}_{2}$ (asterisks) or solar irradiance (triangles) in simulations with the Hadley Centre Slab-Ocean Model version 3. There is a large initial decrease in precipitation in response to $\mathrm{CO}_{2}$ forcing, but the slopes of the subsequent linear responses are similar for the solar and $\mathrm{CO}_{2}$ simulations. Dotted lines show the slopes corresponding to the hydrological sensitivities calculated from the initial and final states [Fig. 7 from Andrews et al. (2009). () American Meteorological Society. Reprinted with permission]

(the solid and dashed lines in Fig. 3), so that the differential dependence of precipitation on temperature is similar.

The linear dependence of precipitation on temperature shown in Fig. 3 suggests that it may be useful to rewrite the atmospheric energy budget (Eq. 1), decomposing the right hand side (and the precipitation change) into a temperature-dependent part $(k \delta T)$ and a temperature-independent part $G$,

$$
L \delta P=k \delta T+G
$$

where $k$ is a constant, and $\delta T$ is the change in global-mean surface temperature (e.g., Allen and Ingram 2002). There are several ways to make this decomposition in practice. Previdi (2010) considers $G$ to include the direct radiative forcing, while $k \delta T$ represents all feedbacks, including the change in surface sensible heat flux. Alternatively, one may decompose the response based on timescale into a "fast" component that occurs before sea surface temperatures (SSTs) respond substantially, and a "slow" component that increases in magnitude as the SSTs change on a multiyear timescale (Yang et al. 2003; Lambert and Faull 2007; Lambert and Webb 2008; Lambert and Allen 2009; Andrews et al. 2009, 2010; Takahashi 2009b; Bala et al. 2010; Andrews and Forster 2010; Frieler et al. 2011). The "slow" and "fast" responses may be calculated using fixed SST simulations or by regressing transient changes in precipitation and temperature (e.g., by calculating the slope and offset of the solid and dashed lines in Fig. 3).

\subsection{Feedbacks}

We first focus on the temperature-dependent part of the precipitation response and ask what physical processes contribute to its magnitude and the range of roughly 1.4-3.4\% $\mathrm{K}^{-1}$ found in modern climate model simulations (Lambert and Webb 2008). 
We make use of the radiative kernel technique (Soden et al. 2008) as applied to feedbacks on global-mean precipitation within the framework of the atmospheric energy budget by Previdi (2010). The simulations used are drawn from the World Climate Research Programme's (WCRP's) Coupled Model Intercomparison Project phase 3 (CMIP3) archive. We present results based on the climate change from 2001-2010 to 2101-2110 under an emissions scenario for greenhouse gases and aerosols (SRES A1B). The feedback analysis quantifies the contributions to $k \delta T$ in Eq. 3 from radiative feedbacks due to changes in tropospheric temperature, water vapor, clouds, and albedo, and from changes in surface sensible heat flux. We further decompose the temperature feedback into a Planck feedback (associated with vertically uniform warming) and a lapse rate feedback (associated with vertically nonuniform warming). We adopt the convention of Previdi (2010) that a positive feedback corresponds to a gain of energy for the atmospheric column and a negative feedback on precipitation. The feedbacks are shown in Fig. 4 for the nine climate models for which the necessary data were available [see Previdi (2010) for details]. This figure may be compared with Fig. 1 of Bony et al. (2006), which shows TOA radiative feedbacks rather than the atmospheric energy budget feedbacks shown here.

The water vapor feedback tends to suppress precipitation as a result of both increased shortwave heating and reduced longwave cooling [Previdi (2010); although Mitchell et al. (1987) and Hall and Manabe (2000) conclude that longwave radiative feedback enhances precipitation under warming based on different simulations and analysis]. The reduced longwave cooling is a residual of opposing effects of increases in specific humidity in the lower troposphere which tend to cool the atmospheric column and increases in specific humidity in the upper troposphere which tend to warm the atmospheric column (Previdi 2010). The effect of changes in water vapor concentrations is, therefore, strongly altitude dependent. Takahashi (2009b) argued that inter-model scatter in the change in clear-sky absorption of shortwave radiation by water vapor is important for inter-model scatter in the precipitation response and that the source of the inter-model scatter was not from different radiative transfer schemes or different changes in the amount of column water vapor. The

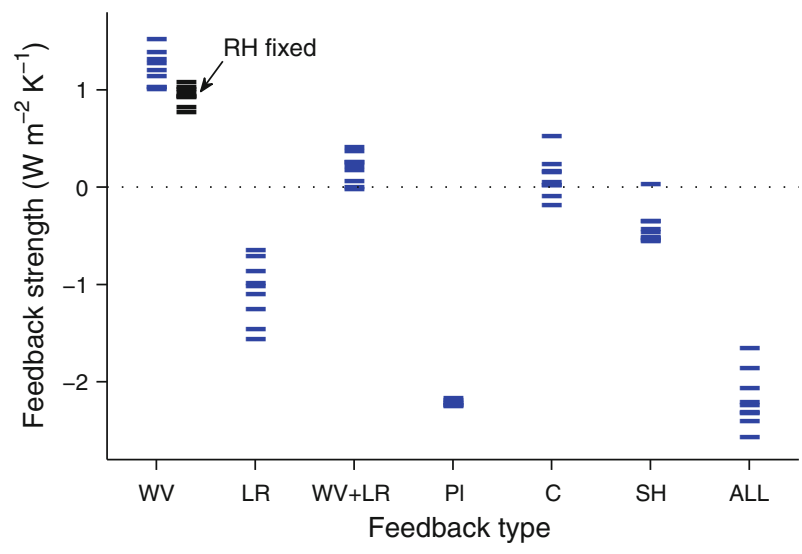

Fig. 4 Feedbacks (blue dashes) on the atmospheric energy budget in coupled simulations with nine climate models. Positive values indicate a gain in energy for the atmospheric column and a negative feedback on precipitation. Feedbacks shown are water vapor (WV), lapse rate (LR), the sum of water vapor and lapse rate (WV + LR), Planck (Pl), cloud (C), surface sensible heat flux (SH), and the sum ALL $=$ WV + LR + $\mathrm{Pl}+\mathrm{C}+\mathrm{SH}$. Albedo feedback is negligible and is not shown. Black dashes show the water vapor feedback for invariant relative humidity $(\mathrm{RH})$ 
water vapor feedback is slightly stronger and has greater inter-model scatter than the feedback that would result from an invariant relative humidity distribution (black dashes in Fig. 4). A consistent pattern of relative humidity changes is found in response to warming in climate model simulations (e.g., Mitchell et al. 1987; Sherwood et al. 2010), and although the fractional changes in relative humidity are not as large as the fractional changes in saturation vapor pressure, they may still be expected to affect radiative fluxes.

The lapse rate feedback is of similar strength to the water vapor feedback, but it tends to enhance precipitation. The magnitudes of the lapse rate and water vapor feedbacks are correlated between models, but they have opposite sign, so that the sum of the two feedbacks (WV + LR) has less inter-model scatter than might otherwise be expected. A similar relationship between lapse rate and water vapor feedbacks has been found for TOA radiative feedbacks (e.g., Bony et al. 2006; Soden et al. 2008).

The cloud feedback is calculated by adjusting the change in cloud radiative forcing to account for cloud-masking effects (Soden et al. 2008; Previdi 2010). It can be positive or negative depending on the model, but tends to suppress precipitation in the multi-model mean. Stephens and Ellis (2008) also found that cloud effects tended to mute the increase in precipitation in the multi-model mean. Although shortwave cloud radiative feedbacks contribute strongly to inter-model scatter in climate sensitivity, they might be expected to have less impact on the atmospheric cooling that controls changes in precipitation (Lambert and Webb 2008). Nonetheless, cloud radiative feedback is the single biggest contributor to inter-model scatter if the water vapor and lapse rate feedbacks are considered as one contribution.

With the exception of one model, the surface sensible heat flux feedback tends to increase precipitation and has relatively little inter-model scatter. The Planck feedback is large in magnitude and has almost the same value in all models considered $(-2.1$ to $-2.2 \mathrm{~W} \mathrm{~m}^{-2} \mathrm{~K}^{-1}$ ). The albedo feedback is very small in magnitude and is not shown. The sum of the feedbacks has a value of $\sim-2 \mathrm{~W} \mathrm{~m}^{-2} \mathrm{~K}^{-1}$ and must be combined with the forcing to give the change in precipitation found in these simulations. Compared with previous analyses of TOA radiative feedbacks (e.g., Bony et al. 2006), some of the primary differences are the negligible albedo feedback, the addition of the surface sensible heat flux, a possibly smaller contribution to scatter from the cloud feedback, and a possibly greater contribution from changes in relative humidity.

\subsection{Dependence on Forcing Agent}

We next consider the dependence of the precipitation response on the nature of the forcing agent. The direct radiative effect of increased concentrations of $\mathrm{CO}_{2}$ is to decrease the net upwelling longwave radiation at the top of the atmosphere (TOA) and increase the net downwelling longwave radiation at the surface, with a net decrease in the radiative loss of the atmosphere [contributing to $G<0$ in Eq. 3] (Ramanathan 1981; Mitchell et al. 1987). Consequently, if surface temperature is held fixed and $\mathrm{CO}_{2}$ concentrations are increased, then global-mean precipitation decreases (e.g., Yang et al. 2003), consistent with Fig. 3. The direct radiative effect of increased insolation is much smaller in the atmospheric energy budget than in the TOA budget since much of the increased shortwave radiation passes through the atmosphere or is scattered back to space. Nonetheless, an increase in insolation does lead to increased shortwave absorption in the atmosphere, which tends to decrease precipitation. Because of the difference in the fast response of precipitation to solar and $\mathrm{CO}_{2}$ forcing (Fig. 3), we expect global-mean precipitation to decrease in an idealized geoengineering experiment in which the effect on global-mean surface 
temperature of higher concentrations of greenhouse gases is offset by the effect of a decrease in solar constant. Bala et al. (2008) find that global-mean precipitation is reduced by $\sim 2 \%$ for a doubling of $\mathrm{CO}_{2}$ in such a geoengineering experiment, which is roughly consistent with what might be inferred from Fig. 3.

Figure 5a [based on Table 2 of Andrews et al. (2010)] shows that the slow temperature-dependent part of the response is quite similar for solar, $\mathrm{CO}_{2}$, and aerosol, forcing, so that the different responses to different forcing agents arises primarily because of the fast component of the response. ${ }^{4}$ Aerosols affect precipitation in a number of different ways (e.g., Ramanathan et al. 2001), but here we will discuss their effect on precipitation through their radiative role in the energetic constraint on precipitation. Figure 5a shows that sulfate aerosols yield a similar precipitation response to solar forcing, as might be expected given that they scatter shortwave radiation. However, increases in the burden of black carbon aerosols may decrease global-mean precipitation even as they increase global-mean surface temperature because of a strongly negative fast response (Fig. 5a).

The negative fast response of precipitation to black carbon aerosols results from absorption of shortwave radiation in the troposphere (induced changes in cloud radiative effects may also play a role). Whether or not the total precipitation response is negative depends on the level in the atmosphere at which the black carbon aerosols occur (Ming et al. 2010; Ban-Weiss et al. 2011). This was demonstrated by Ming et al. (2010) in a set of simulations in which the burden of black carbon aerosols was increased at different levels in the troposphere [Fig. 5b, which is based on Table 1 of Ming et al. (2010)]. Roughly speaking, precipitation decreases when black carbon aerosols are added in the free troposphere, but it increases when they are added near the surface. In all cases shown in Fig. 5b, the surface temperature increases, changes in shortwave absorption provide a negative contribution to the precipitation change, and changes in surface sensible heat flux and temperature provide a positive contribution. ${ }^{5}$ If black carbon aerosols are added near the surface, the increased shortwave absorption is partially canceled by a decrease in the upward sensible heat flux, and precipitation increases because of the increase in radiative cooling related to the increase in temperature. The sensible heat flux response is considerably smaller if the aerosol is added in the free troposphere, and the increase in shortwave heating is then partially balanced by a decrease in latent heating (and precipitation).

The precipitation response to black carbon aerosols is more easily understood using the approximate balance of precipitation and free-atmospheric radiative cooling (Eq. 2) in which radiative heating near the surface and surface sensible heat fluxes do not enter. In the case of the addition of black carbon aerosols near the surface, the only effect on free atmosphere radiative cooling is through the temperature increase, and precipitation increases accordingly. When black carbon aerosols are added higher up in the atmosphere, they directly affect the free-atmospheric radiative heating and precipitation decreases.

\footnotetext{
4 Andrews et al. (2010) show that the temperature dependence of the slow precipitation response is similar for nine different forcing scenarios. The precipitation sensitivities are normalized by a temperature change that is different for the slow and total responses because the fast response includes a change in land surface temperature and the slow response is calculated as the difference between total and fast responses.

5 Ming et al. (2010) consider the change in surface sensible heat flux to be part of the fast or temperatureindependent response.
} 

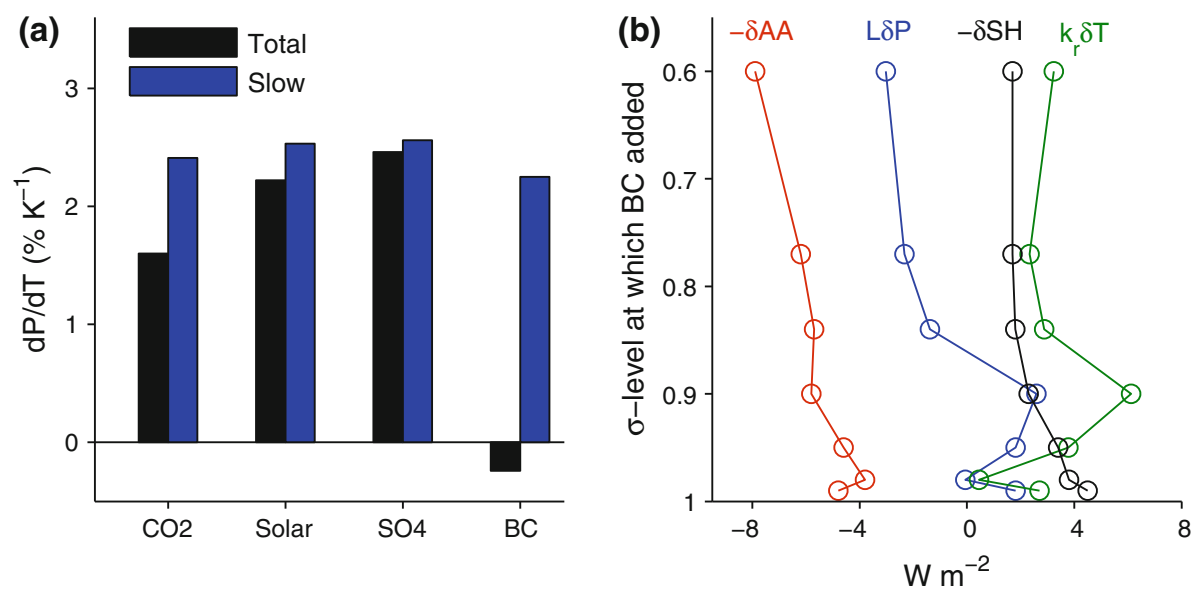

Fig. 5 a Sensitivities of the total and slow precipitation responses for different forcings $\left(\mathrm{CO}_{2}\right.$, solar, sulfate aerosols, and black carbon aerosols) in simulations with an atmospheric model coupled to a mixed-layer ocean. The total response is the sum of the slow and fast responses [based on Table 2 of Andrews et al. (2010)]. b Terms in the perturbation atmospheric energy budget in response to additional black carbon aerosols at different $\sigma$-levels in simulations with an atmospheric GCM coupled to a mixed-layer ocean. The terms shown are the changes in atmospheric absorption induced directly by the absorbing aerosols $(\delta A A)$, radiative feedbacks $\left(k_{r} \delta T\right)$ with surface temperature $T$ and $k_{r}=1.8 \mathrm{~W} \mathrm{~m}^{-2} \mathrm{~K}^{-1}$, the change in latent heating associated with precipitation $L \delta P$, and the change in upward sensible heat flux $(\delta S H)$. We show $-\delta A A$ and $-\delta S H$ so that all terms are positive when contributing to a positive change in precipitation [based on Table 1 of Ming et al. (2010)]

\section{Transient Changes in Precipitation}

The discussion of the preceding section makes clear that changes in surface temperature are not sufficient to determine the equilibrium response of precipitation, but rather that changes in atmospheric radiative forcing must also be specified. Temperature changes may occur on an entirely different timescale to the radiative forcing, and the transient evolution of precipitation depends on the evolution of both radiative forcing and temperature. For example, we expect a slower rate of increase in precipitation with respect to temperature in a period in which both greenhouse-gas concentrations and temperature are increasing than in a period in which greenhouse-gas concentrations have stabilized but temperature continues to increase (Andrews and Forster 2010).

Some further nonintuitive properties of the transient precipitation response have recently been illustrated in coupled climate model simulations (Wu et al. 2010; Cao et al. 2011). Wu et al. (2010) showed that, in response to a change in the trend of atmospheric $\mathrm{CO}_{2}$ concentrations from upward to downward, temperature begins to fall almost immediately, but the rate of increase in precipitation actually accelerates, before eventually decreasing after several decades. Cao et al. (2011) found a similar behavior in response to a rampdown of $\mathrm{CO}_{2}$ concentrations [Fig. 6c; reproduced from Cao et al. (2011)] and also demonstrated an extreme limit of the same behavior in which $\mathrm{CO}_{2}$ concentrations are changed in a step-like manner, first upward and then downward, resulting in downward and then upward spikes in precipitation (red lines in Fig. 6a, b; see also Fig. 3). As discussed by Wu et al. (2010) and Cao et al. (2011), these transient responses may be understood using the energetic constraint on precipitation. For example, a sudden decrease in $\mathrm{CO}_{2}$ concentrations leads to an increase in radiative cooling and an increase in precipitation. Only on the slow timescale of the 

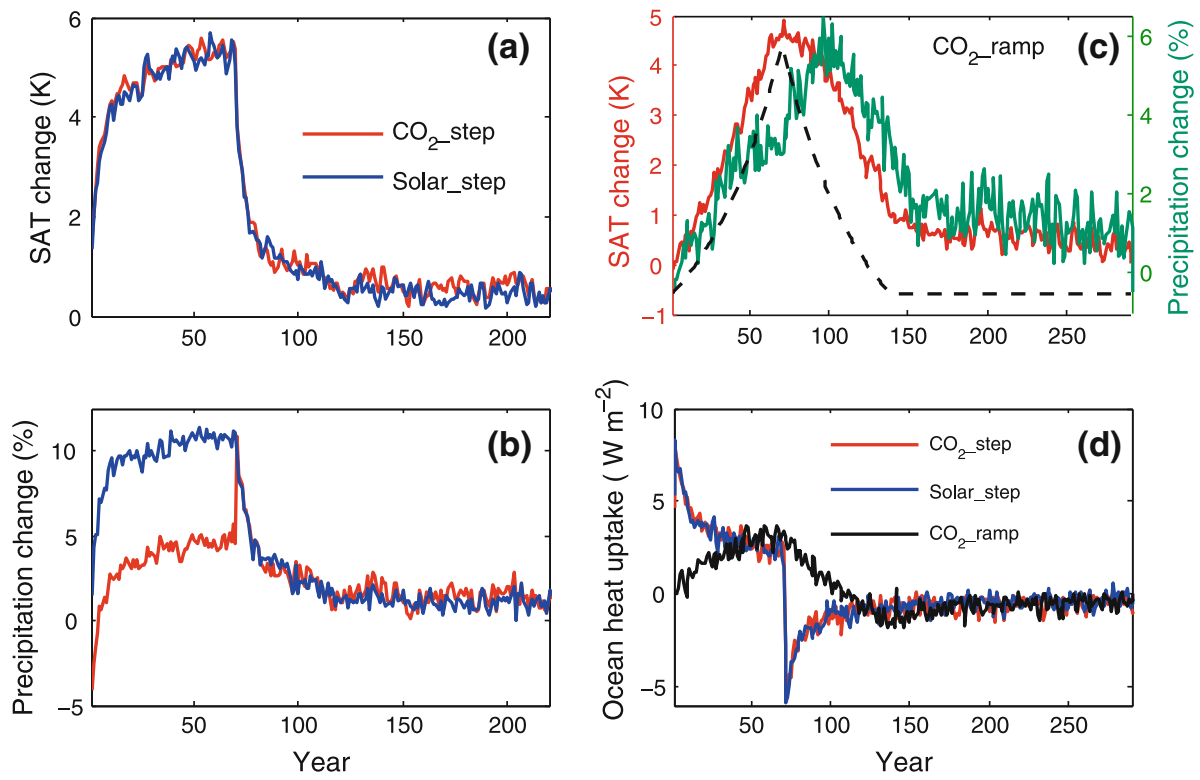

Fig. 6 Temporal variations in a, c surface air temperature, $\mathbf{b}$, $\mathbf{c}$ precipitation, and $\mathbf{d}$ ocean heat uptake in three simulations with a coupled climate model (HadCM3L). In the "step" simulations (a, b, d), atmospheric $\mathrm{CO}_{2}$ or the solar constant are instantaneously increased and then instantaneously returned to their initial value after 70 years $\left(\mathrm{CO}_{2}\right.$ is quadrupled or the solar constant is increased by $\left.4.54 \%\right)$. In the $\mathrm{CO}_{2}$ ramp simulation (c, d), atmospheric $\mathrm{CO}_{2}$ is increased by $2 \%$ per year until quadrupling after 70 years, and then decreased by $2 \%$ per year until the original value is reached [dashed black line in (c)]. Note the downward and upward spikes in precipitation in the $\mathrm{CO}_{2}$ step simulation at years 0 and 70 , respectively [reproduction of Fig. 1 of Cao et al. (2011)]

ensuing temperature decrease does the radiative cooling and precipitation decrease. The precipitation and temperature responses are more qualitatively similar to one another in a simulation in which the step-like changes are in the solar constant (blue lines in Fig. 6a, b), consistent with the much smaller fast response of precipitation for solar forcing. (The magnitude of the changes in solar constant are chosen to give similar surface temperature variations as for the $\mathrm{CO}_{2}$ simulation). From the surface energy budget perspective, the rate of ocean heat uptake should be expected to influence the transient response of evaporation and precipitation. However, the time history of ocean heat uptake is almost identical in the simulations with solar and $\mathrm{CO}_{2}$ step-like changes (Fig. 6d), which shows that the sudden reduction in ocean heat uptake at year 70 is not necessarily sufficient to give a temporary increase in precipitation, depending on the nature of the radiative forcing.

The energetic perspective also makes clear that radiative feedbacks will be important for low-frequency variability of precipitation. For example, Hall and Manabe (2000) found a reduction in the interannual variability of global-mean precipitation in a climate model simulation in which the longwave radiative feedback of water vapor was suppressed.

\section{Regional Changes in Precipitation}

We have focused on the energetic constraint on global-mean precipitation, but regional changes in precipitation are of greater importance for impacts of climate change. Regional 

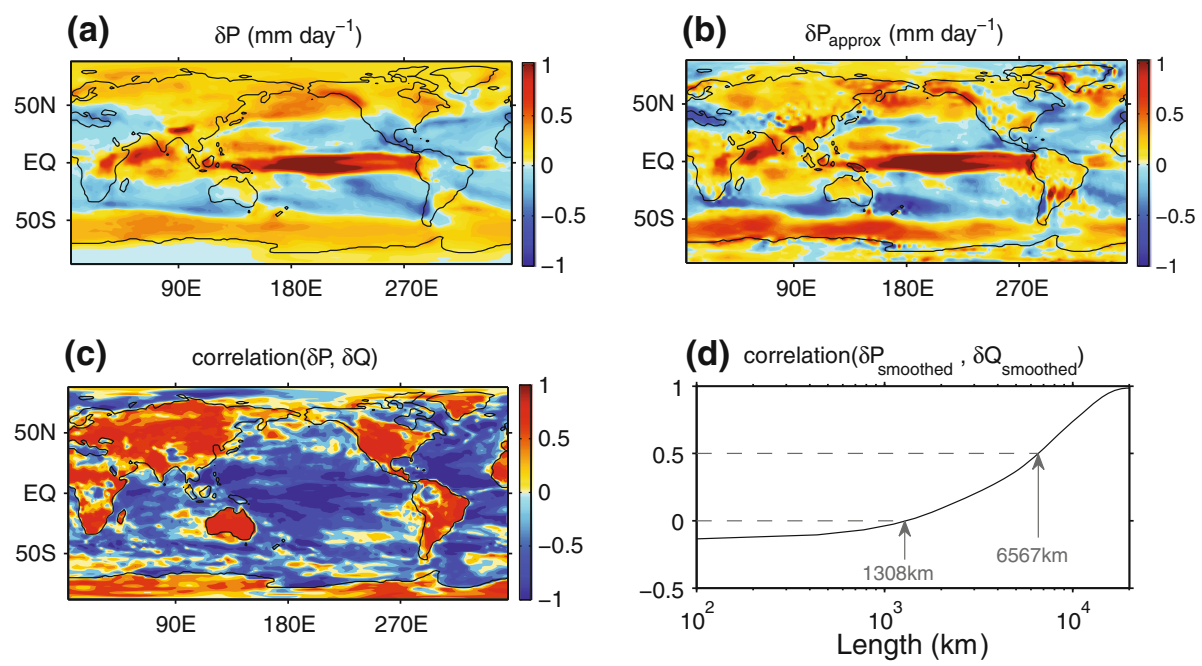

Fig. 7 Energetic perspective on local precipitation changes in the multi-model mean of CMIP3 simulations: a change in precipitation $\left(\mathrm{mm} \mathrm{day}^{-1}\right)$, b an approximation $\delta P_{\text {approx }}=\delta\langle P\rangle+\delta H_{m} / L$ that neglects changes in eddy dry static energy (DSE) fluxes and spatial variations in the change in diabatic cooling, $\mathbf{c}$ the inter-model correlation coefficient of the change in precipitation and diabatic cooling, and d the global-mean of this correlation coefficient as a function of the length scale of a spatial filter that is first applied to the changes in precipitation and diabatic cooling [see Muller and O'Gorman (2011) for details]

precipitation changes have been conventionally analyzed in terms of column water vapor balance, relating the difference between precipitation and evaporation to the water vapor flux convergence (e.g., Held and Soden 2006; Seager et al. 2010). The energy budget has sometimes been used as an additional constraint to account for changes in the circulation which are an important regional contributor to the changes in precipitation (Chou and Neelin 2004; Chou et al. 2009; Levermann et al. 2009; Chou and Chen 2010). Alternatively, the energetic approach to global-mean precipitation changes may be extended to local precipitation changes by including changes in horizontal transports of dry static energy (DSE),

$$
L \delta P=\delta Q+\delta H,
$$

where $\delta H$ is the change in the vertical integral of the DSE flux divergence, and we will refer to $Q=R_{\mathrm{TOA}}-R_{\mathrm{SFC}}-S H$ as the diabatic cooling (excluding latent heating). ${ }^{6}$ The vertical integral in $\delta H$ is taken over the atmospheric column, although it could be approximated by a vertical integral over the troposphere. Increases in DSE flux divergence cool the atmospheric column and tend to increase precipitation for fixed diabatic cooling. Muller and O'Gorman (2011) used this local energy budget to analyze changes in precipitation in simulations drawn from the CMIP3 archive under the A1B emissions scenario (Fig. 7a). They showed that a simple approximation $\delta P_{\text {approx }}$ for the change in local

\footnotetext{
${ }^{6}$ In the case of tropical precipitation extremes, the primary balance is between latent heating and DSE flux divergence (Muller et al. 2011).
} 
precipitation $\delta P$ is given in terms of the change in the vertical integral of the DSE flux divergence by the mean circulation $\left(\delta H_{m}\right)$ and the change in global-mean precipitation $(\delta\langle P\rangle)$, such that $L \delta P_{\text {approx }}=L \delta\langle P\rangle+\delta H_{m}$ (Fig. 7b). Further simple approximations may then be made to relate components of $\delta H_{m}$ to changes in temperature and mid-tropospheric vertical velocity (Muller and O'Gorman 2011), resulting in approximate relations comparable to those used in the water vapor budget approach (e.g., Held and Soden 2006).

Locally, changes in diabatic cooling may be balanced by changes in precipitation or changes in DSE flux divergence. A fundamental question then arises as to what extent local changes in diabatic cooling $\delta Q$ are in fact reflected in local changes in precipitation $\delta P$. For example, one might ask to what extent localized radiative forcing from aerosols will be related to a corresponding local change in precipitation. Muller and O'Gorman (2011) addressed this question by examining the inter-model correlation coefficient between changes in precipitation $\delta P$ and changes in diabatic cooling $\delta Q$ and found that, while $\delta P$ and $\delta Q$ were positively correlated over land, they were negatively correlated over ocean because of cloud and water vapor feedbacks (Fig. 7c). The scale dependency of the relationship between $\delta P$ and $\delta Q$ was addressed by smoothing over a range of length scales prior to calculation of the correlation coefficient. The global-mean correlation coefficient reaches a value of 0.5 for a smoothing length scale of $\sim 7,000 \mathrm{~km}$ (Fig. 7d), implying that only on relatively large scales or over land are $\delta P$ and $\delta Q$ strongly positively correlated. Further work is needed to understand the physical processes that contribute to the correlation between changes in precipitation and diabatic cooling at different length scales and to better understand the contrast between their relationship over land and ocean (cf. Trenberth and Shea 2005; Lambert and Allen 2009).

\section{Observations of the Atmospheric Energetic Constraint on Precipitation}

The energetic constraint on global precipitation is difficult to confirm observationally. Long-term (50 or more years) observations of precipitation (surface rain gauges) are primarily confined to northern hemisphere land regions (e.g., Min et al. 2011), while spatially complete ocean estimates are only available through satellite retrievals of infrared radiances since 1979 and microwave radiances since 1987 (Huffman et al. 2009) and contain substantial uncertainties relating to sampling and calibration (Adler et al. 2001). Reconstructions of past precipitation may be made using reanalyses or surface pressure and temperature measurements (e.g., Arkin et al. 2010), but they are limited by the homogeneity of input data and the physical relationships employed.

Estimates of Earth's radiative energy balance are limited to an even greater extent: satellite data have provided near-global estimates of variability for much of the period since 1985 (Wielicki et al. 2002; Loeb et al. 2009) but with substantial calibration and sampling issues (Trenberth 2002; Wong et al. 2006). Surface measurements are limited to solar radiometers available for a handful of locations over land since the 1950s (Wild 1999), increasing to around 50 well-calibrated longwave and shortwave radiation measurements for the recent decade (Ohmura et al. 1998). Therefore, estimating recent changes in the surface and atmospheric radiative balance is currently possible only through the additional use of reanalyses data sets combined with additional modeling (Zhang et al. 2004).

Current global variability in $P$ and its driving variables are compared in Fig. 8. During this period, global-mean surface air temperature $(T)$ varied by almost $1 \mathrm{~K}$, primarily 
relating to El Niño Southern Oscillation (ENSO), but also a cooling in 1992 following the eruption of Mt. Pinatubo in June 1991 and a warming trend during the 1990s.

\subsection{Observed Changes in Surface Temperature and Water Vapor}

Atmospheric moisture is tightly coupled to global temperatures (Fig. 8a, b) as evidenced by column integrated water vapor $(W)$ from the Special Sensor Microwave Imager [SSM/I; Wentz and Schabel (2000)] and the European Centre for Medium-range Weather Forecasts (ECMWF) Interim ReAnalysis [ERA Interim; Dee et al. (2011)] and also by surfacespecific humidity $(q)$ from HadCRUH observations (Willett et al. 2008). Global SSM/I estimates are constructed using ocean-only SSM/I data between $50^{\circ} \mathrm{S}-50^{\circ} \mathrm{N}$ and applying ERA Interim values elsewhere. ERA Interim $W$ reduces with time compared with the SSM/I estimates, attributable to differences over the tropical oceans (John et al. 2009), and
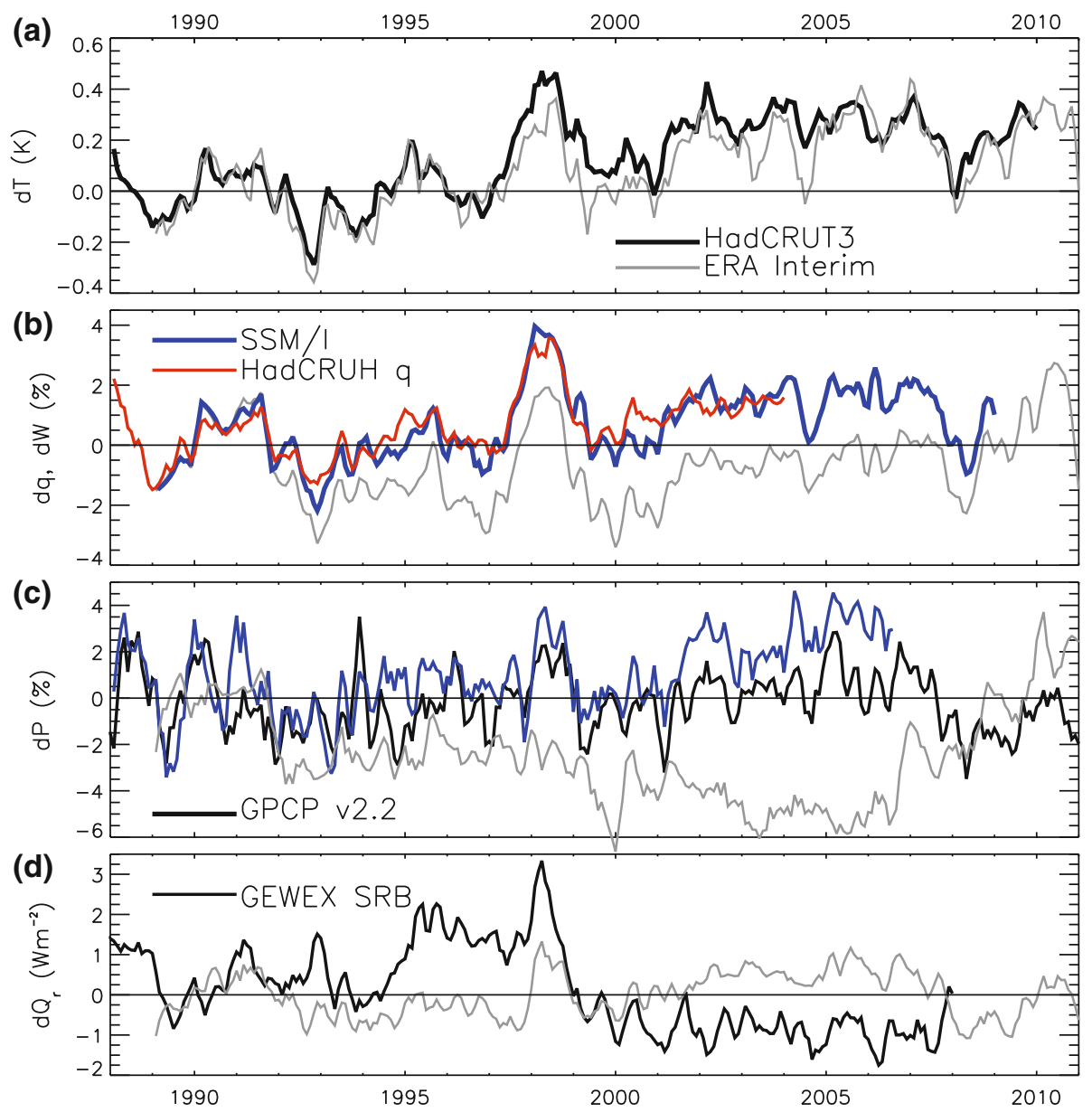

Fig. 8 Global-mean de-seasonalized monthly anomalies in a surface air temperature, b column integrated water vapor and surface-specific humidity, $\mathbf{c}$ precipitation and $\mathbf{d}$ total net radiative cooling of the atmosphere. A 3-month smoothing is applied for clarity. The mean anomaly for January 1989 to December 1990 is subtracted from each time series 
Table 1 Linear least squares fits for selected deseasonalized global-mean monthly variables and data sets over the period 1989-2008

\begin{tabular}{lllll}
\hline Variables $(\mathrm{d} y / \mathrm{d} x)$ & Data set $(y)$ & Data set $(x)$ & $\mathrm{d} y / \mathrm{d} x \pm \mathrm{SE}$ & $r$ \\
\hline $\mathrm{d} W / \mathrm{d} T$ & SSM/I, ERA Interim & HadCRUT & $6.6 \pm 0.4 \% \mathrm{~K}^{-1}$ & 0.87 \\
$\mathrm{~d} P / \mathrm{d} T$ & GPCP & HadCRUT & $3.4 \pm 0.9 \% \mathrm{~K}^{-1}$ & 0.40 \\
$\mathrm{~d} Q_{\mathrm{r}} / \mathrm{d} T$ & ERA Interim & ERA Interim & $2.5 \pm 0.3 \mathrm{~W} \mathrm{~m}^{-2} \mathrm{~K}^{-1}$ & 0.71 \\
$L \mathrm{~d} P / \mathrm{d} Q_{\mathrm{r}}$ & GPCP & ERA Interim & $1.0 \pm 0.2$ & 0.54 \\
\hline
\end{tabular}

may be an artifact of the observing system as documented previously (Trenberth et al. 2001; Allan et al. 2002; Bengtsson et al. 2004).

Similarity between HadCRUH and SSM/I-ERA interim estimates of global moisture variability $(r=0.86)$ is striking, both demonstrating the robust relationship between lowlevel moisture and temperature $\left(\mathrm{d} W / \mathrm{d} T \sim 7 \% \mathrm{~K}^{-1}\right.$; Table 1$)$, close to that expected from the Clausius-Clapeyron equation (O'Gorman and Muller 2010). This has been documented previously using surface observations (Willett et al. 2008), satellite data (Wentz and Schabel 2000; Santer et al. 2007; Allan 2009), and radiosonde soundings (Durre et al. 2009). The dependence of atmospheric water vapor amounts on temperature is important in accounting for observed contrasting regional precipitation responses (Zhang et al. 2007), in particular for the ascending and descending portions of the tropical circulation (Allan et al. 2010) and enhanced tropical seasonality (Chou et al. 2007), and for the observed increase in the intensity of precipitation (Rajeevan et al. 2008; O'Gorman and Schneider 2009a; Zolina et al. 2010; Allan et al. 2010; Min et al. 2011). Importantly for the energetic constraint on precipitation, increases in atmospheric water vapor content are also physically consistent with enhanced longwave radiative cooling of the atmosphere to the surface (Allan 2006; Stephens and Ellis 2008; Philipona et al. 2009) and enhanced shortwave radiative heating of the atmosphere (Allan 2009; Takahashi 2009b).

\subsection{Observed Changes in Precipitation}

Observed global precipitation changes (Fig. 8c) are from the Global Precipitation Climatology Project [GPCP v2.2; Huffman et al. (2009)], which combines infrared and SSM/I microwave radiances over ice-free oceans since 1988 and rain gauges over land, and an estimate from Wentz et al. (2007), who combined SSM/I data over ice-free oceans with GPCP data over remaining regions. Simulated precipitation from ERA Interim is also shown and displays a negative trend up until 2005, as noted by John et al. (2009), and a rapid increase over the period 2006-2010, variations which are known to be erroneous (Dee et al. 2011). Since the hydrological cycle in reanalyses is not well-constrained globally, their representation of decadal changes in water vapor and precipitation is unlikely to be realistic.

Global precipitation from GPCP shows a weak positive relationship with surface temperature from HadCRUT $\left(\mathrm{d} P / \mathrm{d} T=3.4 \% \mathrm{~K}^{-1}\right)$ over the period 1989-2008 (Table 1), similar to values estimated by Adler et al. (2008) for the period 1979-2006. Allowing for autocorrelation using the method of Yang and Tung (1998), which estimates 36 degrees of freedom in the time series, this is only just significant at the $95 \%$ confidence level. The autocorrelation timescale for precipitation (6 months) is notably shorter than for water vapor and net radiation (both around 20 months); the timescale dependence of the 
controlling processes may provide further insight into the role of forcing, feedback, and response (Harries and Futyan 2006).

There is considerable sensitivity of precipitation response to the data set and time period chosen (Quartly et al. 2007; Wang et al. 2008; John et al. 2009). The relationship with temperature changes found above $\left(\mathrm{d} P / \mathrm{d} T=3.4 \% \mathrm{~K}^{-1}\right)$ is weaker than calculated by Wentz et al. (2007), who estimated a $7 \% \mathrm{~K}^{-1}$ response for a shorter time period (Adler et al. 2008), and is also weaker than estimated changes in ocean evaporation (Yu 2007; Li et al. 2011). These estimates were based upon linear trends in precipitation and temperature which introduce substantial uncertainty given the short length of the climate record and the influence of ENSO and volcanic eruptions (Gu et al. 2007; Lambert et al. 2008); the estimated observed responses are, therefore, not inconsistent with the large spread in responses calculated from climate models using similar methods (Previdi and Liepert 2008; Liepert and Previdi 2009; Allan 2009). The larger response over the period 1987-2006 (Wentz et al. 2007) may be consistent with an apparent intensification of the Walker and Hadley circulation since 1979 (Sohn and Park 2010; Zahn and Allan 2011; Li et al. 2011) although declines in circulation have also been identified by other authors (Vecchi et al. 2006; Power and Smith 2007; Gastineau and Soden 2011), based upon reanalyses and satellite wind data. A blended reconstruction of twentieth century precipitation by Arkin et al. (2010), based upon gauge observations over land and surface temperature and pressure patterns over ocean, suggests a smaller hydrological sensitivity of $2.5 \% \mathrm{~K}^{-1}$.

\subsection{Estimating Net Radiative Cooling}

The energetic constraint on precipitation discussed in previous sections implies that changes in global-mean precipitation depend both on changes in the radiative cooling of the atmosphere and changes in surface sensible heat flux. As discussed in Sect. 2, the net atmospheric radiative cooling above the sub-cloud layer may provide a more direct link to global-mean precipitation (Takahashi 2009a), but given the difficulties of generating such a data set, we instead use the approach of Allan (2006) and show estimates of the net radiative cooling of the atmosphere $\left(Q_{\mathrm{r}}\right.$, longwave radiative cooling minus shortwave radiative heating) in Fig. 8d.

There is poor agreement between estimates of $Q_{\mathrm{r}}$ from the NASA Global Energy and Water Cycle Experiment (GEWEX) Surface Radiation Budget (SRB) project, which uses cloud and radiation information retrieved from satellite and atmospheric profiles from reanalyses as input to radiative transfer models (Stackhouse et al. 2011) and the ERA Interim reanalysis project. Variability from the International Satellite Cloud Climatology Project (ISCCP) D2 radiative flux products (Zhang et al. 2004) is substantially larger (not shown), showing poor agreement with SRB and ERA Interim. John et al. (2009) also found larger differences in atmospheric longwave and shortwave radiative divergence between data sets for the tropical ocean. One of the problems with the approach adopted by SRB and ISCCP is that surface radiative fluxes are not well constrained by the satellite measurements, in particular for the longwave fluxes, and homogeneity of the ISCCP data set is questionable (Evan et al. 2007).

Although ERA Interim clouds are generated by model parameterizations, the simulation of changes in net radiation at the top of the atmosphere is reasonable based upon comparison with satellite data (Allan 2011) and, notwithstanding issues with drifts in $W$ shown in Fig. $8 \mathrm{~b}$ and the lack of account for changes in aerosol optical depth, appear physically reasonable based upon the relationship with surface temperature $\left(\mathrm{d} Q_{\mathrm{r}} / \mathrm{d} T=\right.$ $2.5 \mathrm{~W} \mathrm{~m}^{-2} \mathrm{~K}^{-1}$, Table 1) and previous analysis (Allan 2009; John et al. 2009). Although 
clouds contribute to heating of the moist tropical troposphere and cooling of the atmospheric column for stratocumulus regions and higher latitudes (Sohn 1999), their impact upon decadal changes in the atmospheric radiative budget may be weak, as discussed by John et al. (2009). (For climate models, Fig. 4 shows that the cloud radiative feedback on precipitation is not different from zero to within the inter-model scatter.)

\subsection{Observed Link Between Precipitation and Atmospheric Net Radiative Cooling}

The relationship between GPCP $P$ (converted into units of $\mathrm{W} \mathrm{m}^{-2}$ by multiplying by the latent heat of condensation $L$ ) and ERA Interim $Q_{\mathrm{r}}, L \mathrm{~d} P / \mathrm{d} Q_{\mathrm{r}}=1.0 \pm 0.2$, is weak (Table 1) although statistically significant at the 95\% confidence level allowing for autocorrelation and it is also physically reasonable. Accounting more carefully for changes in aerosol, cloud and water vapor may improve the observational constraint on precipitation changes. For example, decadal trends in aerosol optical depth associated with global "dimming" and "brightening" (Wild et al. 2005; Mishchenko et al. 2007) are thought to explain increases in rainfall over land during the 1990s (Wild et al. 2008; Wild and Liepert 2010).

Within the framework of the atmospheric energy budget constraint on precipitation, scattering aerosols influence atmospheric radiative cooling and precipitation through the surface temperature response, but absorbing aerosols also directly lead to radiative heating of the atmosphere and thus may affect precipitation independent of surface temperature changes (Lambert et al. 2008; Andrews et al. 2009; Ming et al. 2010; Ban-Weiss et al. 2011), as discussed in Sect. 4.2. A further influence on hydrological sensitivity relates to greenhouse gases. Decadal trends in $P$ are influenced by the secular rises in $\mathrm{CO}_{2}$ concentrations which act in a similar way to absorbing aerosols by radiatively heating the atmosphere. Based upon these arguments, rising $\mathrm{CO}_{2}$ concentrations in the 2000 s, combined with stable decadal temperature, should result in a negative precipitation trend; this is not immediately obvious from Fig. 8c.

\section{Conclusions}

We have given a review of many of the insights to be gained from the energetic perspective on the response of precipitation to climate change. A number of open questions remain, several of which we now discuss briefly.

While it is clear that the atmospheric energy budget constrains the possible changes in global-mean precipitation, especially in warm climates, there is still some uncertainty as to the nature of the constraint. For example, we have discussed whether it may be approximated as a purely radiative constraint by balancing latent heating with the radiative cooling of the free atmosphere. Results presented here based on simulations with an idealized GCM over a wide range of climates provide some support for this free-atmospheric radiative constraint. Further work is needed to evaluate its accuracy, although the necessary radiative fluxes near the top of the boundary layer are not readily available in global observational or climate model data sets. It would be straightforward to further test the accuracy of the free-atmospheric radiative constraint using simulations with a comprehensive climate model in which the necessary radiative fluxes were stored. Even if the freeatmospheric radiative constraint is not very accurate, it may still be useful conceptually. For example, we have shown that it gives a particularly simple explanation for the simulated response of precipitation to radiative forcing from black carbon aerosols (Sect. 4.2). 
Considerable progress has been made in quantifying the different feedbacks that contribute to changes in global-mean precipitation. The results presented here [extending the analysis of Previdi (2010)] suggest that cloud radiative feedbacks are a primary contributor to the inter-model scatter in the response of precipitation. Further characterization of the sources of uncertainty in the response of precipitation is desirable, with the aim of clarifying the extent to which these are similar to the sources of uncertainty for climate sensitivity and of identifying the processes whose parameterization is most problematic in this context. The need to include the changes in surface sensible heat fluxes (unless the free-atmospheric radiative constraint is proven adequate) distinguishes the problem from that of TOA radiative feedbacks, and it is important to develop a better understanding of the response of surface sensible heat fluxes on different timescales and for different forcings (cf., Liepert and Previdi 2009).

The different responses to different forcing agents have also been described, including recent progress in quantifying the fast response of precipitation to different types of aerosol forcing. The vertical structure of changes in water vapor, black carbon aerosols, and clouds is expected to be important in determining the magnitude and even the sign of the precipitation response. The combination of slow and fast responses means that it is not necessarily straightforward to relate observed or simulated transient changes in precipitation to changes in temperature. An intriguing possibility is that it is more appropriate to relate changes in precipitation to changes in radiative forcing rather than changes in temperature; in addition to the closer agreement then found between hydrological sensitivities for different forcing agents (Lambert and Faull 2007), it may be more appropriate to relate changes in energy fluxes to one another than to changes in temperature.

We have discussed how the energetic perspective on global-mean precipitation changes may be extended to regional precipitation changes by including horizontal energy fluxes (DSE fluxes) in the analysis. One important question that could be addressed in such a framework is the extent to which energetics can be used to give a simple constraint on changes in precipitation over land (for example, in terms of radiative forcings and changes in surface temperature). Such a constraint would be particularly useful because many of the available historical observations of precipitation are over land rather than ocean. Lambert and Allen (2009) found that a simple regression model for precipitation changes that was adequate in the global-mean was not adequate over land alone, even when land-ocean energy transports were accounted for. Nonetheless, starting from the full local energy budget, it should be possible to systematically make approximations to derive the minimal energetic model needed to account for changes in precipitation over land.

Currently available observations do not allow us to definitively link changes in globalmean precipitation with changes in the radiative energy budget of the atmosphere. Uncertainties arise for both the observed changes in radiative fluxes and precipitation, and more extensive and longer-term observations are clearly desirable. The observations we do have raise a number of important questions. For example, what sets the different autocorrelation timescales of global-mean precipitation, column water vapor, and net radiative cooling? And what are the contributions of different forcing agents to the observed hydrological sensitivity over different time periods? These basic questions are important for understanding observations of ongoing changes in the global hydrological cycle.

Progress could be made on several of the open questions identified here using simulations which have recently become available from the Coupled Model Intercomparison Project phase 5. In particular, the experiments designed to probe fast and slow responses and the impacts of changes in clouds and aerosols could be used to better understand precipitation responses in different models and emissions scenarios. 
Acknowledgments M. Byrne is supported through the MIT Joint Program on the Science and Policy of Global Change. R. Allan is funded through the National Environment Research Council PREPARE project (NE/G015708/1) and National Centre for Atmospheric Sciences. We thank the American Meteorological Society (AMS) and T. Andrews for reproduction of Fig. 3, the American Geophysical Union (AGU) and L. Cao for reproduction of Fig. 6, and C. J. Muller for Fig. 7. The SSM/I data were extracted from Remote Sensing Systems, the GPCP data from the NASA Goddard Space Flight Center, the HadCRUH and HadCRUT data from http://www.metoffice.gov.uk/hadobs/ and ERA Interim data from http://www.ecmwf.int. We acknowledge the modeling groups, the Program for Climate Model Diagnosis and Intercomparison (PCMDI) and the WCRP's Working Group on Coupled Modelling (WGCM) for their roles in making available the WCRP CMIP3 multi-model data set. Support of this data set is provided by the Office of Science, US Department of Energy.

\section{References}

Adler RF, Kidd C, Petty G, Morissey M, Goodman HM (2001) Intercomparison of global precipitation products: the third precipitation intercomparison project (PIP-3). Bull Am Meteorol Soc 82:1377-1396

Adler RF, Gu G, Wang JJ, Huffman GJ, Curtis S, Bolvin D (2008) Relationships between global precipitation and surface temperature on interannual and longer timescales (1979-2006). J Geophys Res 113:D22,104

Allan RP (2006) Variability in clear-sky longwave radiative cooling of the atmosphere. J Geophys Res 111:D22, 105

Allan RP (2009) Examination of relationships between clear-sky longwave radiation and aspects of the atmospheric hydrological cycle in climate models, reanalyses, and observations. J Clim 22:3127-3145

Allan RP (2011) Combining satellite data and models to estimate cloud radiative effect at the surface and in the atmosphere. Meteorol Appl 18:324-333

Allan RP, Slingo A, Ramaswamy V (2002) Analysis of moisture variability in the European Centre for medium-range weather forecasts 15-year reanalysis over the tropical oceans. J Geophys Res 107:4230

Allan RP, Soden BJ, John VO, Ingram WI, Good P (2010) Current changes in tropical precipitation. Environ Res Lett 5:025205

Allen MR, Ingram WJ (2002) Constraints on future changes in climate and the hydrologic cycle. Nature 419:224-232

Andrews T, Forster PM (2010) The transient response of global-mean precipitation to increasing carbon dioxide levels. Environ Res Lett 5:025212

Andrews T, Forster PM, Gregory JM (2009) A surface energy perspective on climate change. J Clim 22:2557-2570

Andrews T, Forster PM, Boucher O, Bellouin N, Jones A (2010) Precipitation, radiative forcing and global temperature change. Geophys Res Lett 37:L14701

Arkin PA, Smith TM, Sapiano MRP, Janowiak J (2010) The observed sensitivity of the global hydrological cycle to changes in surface temperature. Environ Res Lett 5:035201

Bala G, Duffy PB, Taylor KE (2008) Impact of geoengineering schemes on the global hydrological cycle. Proc Nat Acad Sci 105:7664-7669

Bala G, Caldeira K, Nemani R (2010) Fast versus slow response in climate change: implications for the global hydrological cycle. Clim Dyn 35:423-434

Ban-Weiss GA, Cao L, Bala G, Caldeira K (2011) Dependence of climate forcing and response on the altitude of black carbon aerosols. Clim Dyn doi:10.1007/s00382-011-1052-y

Bengtsson L, Hagemann S, Hodges KI (2004) Can climate trends be calculated from reanalysis data?. J Geophys Res 109:D11111

Boer GJ (1993) Climate change and the regulation of the surface moisture and energy budgets. Clim Dyn $8: 225-239$

Bony S, Colman R, Kattsov VM, Allan RP, Bretherton CS, Dufresne JL, Hall A, Hallegatte S, Holland MM, Ingram W, Randall DA, Soden BJ, Tselioudis G, Webb MJ (2006) How well do we understand and evaluate climate change feedback processes?. J Clim 19:3445-3482

Cao L, Bala G, Caldeira K (2011) Why is there a short-term increase in global precipitation in response to diminished $\mathrm{CO}_{2}$ forcing?. Geophys Res Lett 38:L06703

Chou C, Chen CA (2010) Depth of convection and the weakening of tropical circulation in global warming. J Clim 23:3019-3030

Chou C, Neelin JD (2004) Mechanisms of global warming impacts on regional tropical precipitation. J Clim $17: 2688-2701$ 
Chou C, Tu JY, Tan PH (2007) Asymmetry of tropical precipitation change under global warming. Geophys Res Lett 34:L17708

Chou C, Neelin JD, Chen CA, Tu JY (2009) Evaluating the "Rich-Get-Richer" mechanism in tropical precipitation change under global warming. J Clim 22:1982-2005

Dee DP, Uppala SM, Simmons AJ, Berrisford P, Poli P, Kobayashi S, Andrae U, Balmaseda MA, Balsamo G, Bauer P, Bechtold P, Beljaars ACM, van de Berg L, Bidlot J, Bormann N, Delsol C, Dragani R, Fuentes M, Geer AJ, Haimberger L, Healy SB, Hersbach H, Hólm EV, Isaksen L, Kållberg P, Köhler M, Matricardi M, McNally AP, Monge-Sanz BM, Morcrette JJ, Park BK, Peubey C, de Rosnay P, Tavolato C, Thépaut JN, Vitart F (2011) The ERA-Interim reanalysis: configuration and performance of the data assimilation system. Q J R Meteorol Soc 137:553-597

Durre I, Williams CN Jr, Yin X, Vose RS (2009) Radiosonde-based trends in precipitable water over the Northern Hemisphere: an update. J Geophys Res 114:D05112

Evan AT, Heidinger AK, Vimont DJ (2007) Arguments against a physical long-term trend in global ISCCP cloud amounts. Geophys Res Lett 34:L04701

Frieler K, Meinshausen M, von Deimling TS, Andrews T, Forster P (2011) Changes in global-mean precipitation in response to warming, greenhouse gas forcing and black carbon. Geophys Res Lett 38:L04702

Frierson DMW (2007) The dynamics of idealized convection schemes and their effect on the zonally averaged tropical circulation. J Atmos Sci 64:1959-1976

Frierson DMW, Held IM, Zurita-Gotor P (2006) A gray-radiation aquaplanet moist GCM. Part I: static stability and eddy scale. J Atmos Sci 63:2548-2566

Gastineau G, Soden BJ (2011) Evidence for a weakening of tropical surface wind extremes in response to atmospheric warming. Geophys Res Lett 38:L09706

Gu G, Adler RF, Huffman GJ, Curtis S (2007) Tropical rainfall variability on interannual-to-interdecadal and longer time scales derived from the GPCP monthly product. J Clim 20:4033-4046

Hall A, Manabe S (2000) Effect of water vapor feedback on internal and anthropogenic variations of the global hydrologic cycle. J Geophys Res 105:6935-6944

Harries JE, Futyan JM (2006) On the stability of the Earth's radiative energy balance: response to the Mt. Pinatubo eruption. Geophys Res Lett 33:L23814

Held IM, Soden BJ (2006) Robust responses of the hydrological cycle to global warming. J Clim 19:5686-5699

Huffman GJ, Adler RF, Bolvin DT, Gu G (2009) Improving the global precipitation record: GPCP version 2.1. Geophys Res Lett 36:L17808

John VO, Allan RP, Soden BJ (2009) How robust are observed and simulated precipitation responses to tropical ocean warming. Geophys Res Lett 36:L14702

Lambert FH, Allen MR (2009) Are changes in global precipitation constrained by the tropospheric energy budget?. J Clim 22:499-517

Lambert FH, Faull NE (2007) Tropospheric adjustment: the response of two general circulation models to a change in insolation. Geophys Res Lett 34:L03701

Lambert FH, Webb MJ (2008) Dependency of global mean precipitation on surface temperature. Geophys Res Lett 35:L16706

Lambert FH, Stine AR, Krakauer NY, Chiang JCH (2008) How much will precipitation increase with global warming?. Eos Trans AGU 89:193-194

Le Hir G, Donnadieu Y, Goddéris Y, Pierrehumbert RT, Halverson GP, Macouin M, Nédélec A, Ramstein G (2009) The snowball Earth aftermath: exploring the limits of continental weathering processes. Earth Planet Sci Lett 277:453-463

Levermann A, Schewe J, Petoukhov V, Held H (2009) Basic mechanism for abrupt monsoon transitions. Proc Nat Acad Sci 106:20,572-20,577

Li G, Ren B, Yang C, Zheng J (2011) Revisiting the trend of the tropical and subtropical Pacific surface latent heat flux during 1977-2006. J Geophys Res 116:D10115

Liepert BG, Previdi M (2009) Do models and observations disagree on the rainfall response to global warming?. J Clim 22:3156-3166

Loeb NG, Wielicki BA, Doelling DR, Smith GL, Keyes DF, Kato S, Manalo-Smith N, Wong T (2009) Toward optimal closure of the Earth's top-of-atmosphere radiation budget. J Clim 22:748-766

Lorenz DJ, DeWeaver ET, Vimont DJ (2010) Evaporation change and global warming: the role of net radiation and relative humidity. J Geophys Res 115:D20118

Min SK, Zhang X, Zwiers FW, Hegerl GC (2011) Human contribution to more-intense precipitation extremes. Nature 470:378-381

Ming Y, Ramaswamy V, Persad G (2010) Two opposing effects of absorbing aerosols on global-mean precipitation. Geophys Res Lett 37:L13701 
Mishchenko MI, Geogdzhayev IV, Rossow WB, Cairns B, Carlson BE, Lacis AA, Liu L, Travis LD (2007) Long-term satellite record reveals likely recent aerosol trend. Science 315:1543

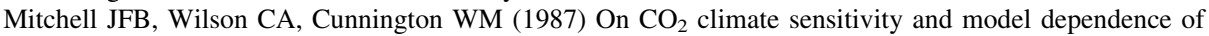
results. Q J R Meteorol Soc 113:293-322

Muller CJ, O'Gorman PA (2011) An energetic perspective on the regional response of precipitation to climate change. Nat Clim Change 1:266-271

Muller CJ, O'Gorman PA, Back LE (2011) Intensification of precipitation extremes with warming in a cloud resolving model. J Clim 24:2784-2800

O'Gorman PA, Muller CJ (2010) How closely do changes in surface and column water vapor follow Clausius-Clapeyron scaling in climate-change simulations?. Environ Res Lett 5:025207

O'Gorman PA, Schneider T (2008) The hydrological cycle over a wide range of climates simulated with an idealized GCM. J Clim 21:3815-3832

O'Gorman PA, Schneider T (2009a) The physical basis for increases in precipitation extremes in simulations of 21st-century climate change. Proc Natl Acad Sci 106:14,773-14,777

O'Gorman PA, Schneider T (2009b) Scaling of precipitation extremes over a wide range of climates simulated with an idealized GCM. J Clim 22:5676-5685

Ohmura A, Dutton EG, Forgan B, Fröhlich C, Gilgen H, Hegner H, Heimo A, König-Langlo G, McArthur B, Müller G, Philipona R, Pinker R, Whitlock CH, Dehne K, Wild M (1998) Baseline surface radiation network (BSRN/WCRP): new precision radiometry for climate research. Bull Am Meteorol Soc 79:2115-2136

Pall P, Allen MR, Stone DA (2007) Testing the Clausius-Clapeyron constraint on changes in extreme precipitation under $\mathrm{CO}_{2}$ warming. Clim Dyn 28:351-363

Peixoto JP, Oort AH (1992) Physics of climate. American Institute of Physics, New York

Philipona R, Behrens K, Ruckstuhl C (2009) How declining aerosols and rising greenhouse gases forced rapid warming in Europe since the 1980s. Geophys Res Lett 36:L02806

Pierrehumbert RT (1999) Subtropical water vapor as a mediator of rapid global climate change. In: Clarks PU, Webb RS, Keigwin LD (eds) Mechanisms of global climate change at millennial time scales. Geophys. Monogr. Ser., vol 112, American Geophysical Union, Washington, p 339

Pierrehumbert RT (2002) The hydrologic cycle in deep-time climate problems. Nature 419:191-198

Power SB, Smith IN (2007) Weakening of the Walker circulation and apparent dominance of El Niño both reach record levels, but has ENSO really changed?. Geophys Res Lett 34:L18702

Previdi M (2010) Radiative feedbacks on global precipitation. Environ Res Lett 5:025211

Previdi M, Liepert BG (2008) Interdecadal variability of rainfall on a warming planet. Eos Trans AGU 89:193-195

Quartly GD, Kyte EA, Srokosz MA, Tsimplis MN (2007) An intercomparison of global oceanic precipitation climatologies. J Geophys Res 112:D10121

Rajeevan M, Bhate J, Jaswal AK (2008) Analysis of variability and trends of extreme rainfall events over India using 104 years of gridded daily rainfall data. Geophys Res Lett 35:L18707

Ramanathan V (1981) The role of ocean-atmosphere interactions in the $\mathrm{CO}_{2}$ climate problem. J Atmos Sci 38:918-930

Ramanathan V, Crutzen PJ, Kiehl JT, Rosenfeld D (2001) Aerosols, climate, and the hydrological cycle. Science 294:2119-2124

Richter I, Xie SP (2008) Muted precipitation increase in global warming simulations: A surface evaporation perspective. J Geophys Res 113:D24118

Romps DM (2011) Response of tropical precipitation to global warming. J Atmos Sci 68:123-138

Santer BD, Mears C, Wentz FJ, Taylor KE, Gleckler PJ, Wigley TML, Barnett TP, Boyle JS, Brüggemann W, Gillett NP, Klein SA, Meehl GA, Nozawa T, Pierce DW, Stott PA, Washington WM, Wehner MF (2007) Identification of human-induced changes in atmospheric moisture content. Proc Natl Acad Sci $104: 15,248-15,253$

Schneider T, O'Gorman PA, Levine XJ (2010) Water vapor and the dynamics of climate changes. Rev Geophys 48:RG3001

Seager R, Naik N, Vecchi GA (2010) Thermodynamic and dynamic mechanisms for large-scale changes in the hydrological cycle in response to global warming. J Clim 23:4651-4668

Sherwood SC, Ingram W, Tsushima Y, Satoh M, Roberts M, Vidale PL, O'Gorman PA (2010) Relative humidity changes in a warmer climate. J Geophys Res 115:D09104

Soden BJ, Held IM, Colman R, Shell KM, Kiehl JT, Shields CA (2008) Quantifying climate feedbacks using radiative kernels. J Clim 21:3504-3520

Sohn BJ (1999) Cloud-induced infrared radiative heating and its implications for large-scale tropical circulations. J Atmos Sci 56:2657-2672 
Sohn BJ, Park SC (2010) Strengthened tropical circulations in past three decades inferred from water vapor transport. J Geophys Res 115:D15112

Stackhouse PW Jr, Gupta SK, Cox SJ, Zhang T, Mikovitz JC, Hinkelman LM (2011) 24.5-year SRB data set released. GEWEX News 21:10-12

Stephens GL, Ellis TD (2008) Controls of global-mean precipitation increases in global warming GCM experiments. J Clim 21:6141-6155

Stephens GL, Hu Y (2010) Are climate-related changes to the character of global-mean precipitation predictable?. Environ Res Lett 5:025209

Stevens B, Schwartz SE (2011) Observing and modeling Earth's energy flows. Surv Geophys (submitted)

Sun Y, Solomon S, Dai A, Portmann RW (2007) How often will it rain?. J Clim 20:4801-4818

Takahashi K (2009a) Radiative constraints on the hydrological cycle in an idealized radiative-convective equilibrium model. J Atmos Sci 66:77-91

Takahashi K (2009b) The global hydrological cycle and atmospheric shortwave absorption in climate models under $\mathrm{CO}_{2}$ forcing. J Clim 22:5667-5675

Trenberth KE (1999) Conceptual framework for changes of extremes of the hydrological cycle with climate change. Clim Change 42:327-339

Trenberth KE (2002) Changes in tropical clouds and radiation. Science 296:2095a

Trenberth KE (2011) Changes in precipitation with climate change. Clim Res 47:123-138

Trenberth KE, Shea DJ (2005) Relationships between precipitation and surface temperature. Geophys Res Lett 32:L14703

Trenberth KE, Stepaniak DP, Hurrell JW, Fiorino M (2001) Quality of reanalyses in the tropics. J Clim 14:1499-1510

Trenberth KE, Dai A, Rasmussen RM, Parsons DB (2003) The changing character of precipitation. Bull Am Meteorol Soc 84:1205-1217

Trenberth KE, Fasullo JT, Kiehl J (2009) Earth's global energy budget. Bull Am Meteorol Soc 90:311-323

Vecchi GA, Soden BJ, Wittenberg AT, Held IM, Leetmaa A, Harrison MJ (2006) Weakening of tropical Pacific atmospheric circulation due to anthropogenic forcing. Nature 441:73-76

Wang JJ, Adler RF, Gu G (2008) Tropical rainfall-surface temperature relations using Tropical Rainfall Measuring Mission precipitation data. J Geophys Res 113:D18115

Wentz FJ, Schabel M (2000) Precise climate monitoring using complementary satellite data sets. Nature 403:414-416

Wentz FJ, Ricciardulli L, Hilburn K, Mears C (2007) How much more rain will global warming bring?. Science 317:233-235

Wielicki BA, Wong T, Allan RP, Slingo A, Kiehl JT, Soden BJ, Gordon CT, Miller AJ, Yang S, Randall DA, Robertson F, Susskind J, Jacobowitz H (2002) Evidence for large decadal variability in the tropical mean radiative energy budget. Science 295:841-844

Wild M (1999) Discrepancies between model-calculated and observed shortwave atmospheric absorption in areas with high aerosol loadings. J Geophys Res 104:27,361-27,371

Wild M, Liepert B (2010) The Earth radiation balance as driver of the global hydrological cycle. Environ Res Lett 5:025003

Wild M, Gilgen H, Roesch A, Ohmura A, Long CN, Dutton EG, Forgan B, Kallis A, Russak V, Tsvetkov A (2005) From dimming to brightening: decadal changes in solar radiation at Earth's surface. Science 308:847-850

Wild M, Grieser J, Schär C (2008) Combined surface solar brightening and increasing greenhouse effect support recent intensification of the global land-based hydrological cycle. Geophys Res Lett 35:L17706

Willett KM, Jones PD, Gillett NP, Thorne PW (2008) Recent changes in surface humidity: development of the HadCRUH dataset. J Clim 21:5364-5383

Wong T, Wielicki BA, Lee RB, Smith GL, Bush KA, Willis JK (2006) Reexamination of the observed decadal variability of the Earth radiation budget using altitude-corrected ERBE/ERBS nonscanner WFOV data. J Clim 19:4028-4040

Wu P, Wood R, Ridley J, Lowe J (2010) Temporary acceleration of the hydrological cycle in response to a $\mathrm{CO}_{2}$ rampdown. Geophys Res Lett 37:L12705

Yang F, Kumar A, Schlesinger ME, Wang W (2003) Intensity of hydrological cycles in warmer climates. J Clim 16:2419-2423

Yang H, Tung KK (1998) Water vapor, surface temperature, and the greenhouse effect-a statistical analysis of tropical-mean data. J Clim 11:2686-2697

Yu L (2007) Global variations in oceanic evaporation (1958-2005): the role of the changing wind speed. J Clim 20:5376-5390

Zahn M, Allan RP (2011) Changes in water vapor transports of the ascending branch of the tropical circulation. J Geophys Res 116:D18111 
Zhang X, Zwiers FW, Hegerl GC, Lambert FH, Gillett NP, Solomon S, Stott PA, Nozawa T (2007) Detection of human influence on twentieth-century precipitation trends. Nature 448:461-465

Zhang Y, Rossow WB, Lacis AA, Oinas V, Mishchenko MI (2004) Calculation of radiative fluxes from the surface to top of atmosphere based on ISCCP and other global data sets: refinements of the radiative transfer model and the input data. J Geophys Res 109:D19105

Zolina O, Simmer C, Gulev SK, Kollet S (2010) Changing structure of European precipitation: longer wet periods leading to more abundant rainfalls. Geophys Res Lett 37:L06704 